\title{
On the usefulness of government spending in the EU area
}

\author{
Luigi Marattin ${ }^{ \pm}$
}

\author{
Simone Salotti $\div$
}

This draft: December 2009

\begin{abstract}
We investigate the effects of fiscal policy on private consumption and investment in the European Union. A certain consensus has aroused that fiscal impulses have expansionary Keynesian effects on the economic activity. However, the existing empirical literature has concentrated on few countries, mostly outside the EU. We check the validity of this result for the EU area, by using annual data and a panel vector auto-regression approach (PVAR). Our results show that increases in public spending lead to positive and significant effects on private consumption and private investment. According to our baseline estimate, a $1 \%$ increase in public spending produces a $0.26 \%$ on impact rise in private consumption, and a $0.43 \%$ impact rise in private investment. The effects are substantial, and die out slowly in the case of private consumption ( $0.63 \%$ cumulative impact after 3 years), but much faster in the case of private investment. A further disaggregation between wage and non-wage components reveals that public salaries have a relatively stronger stimulating role, a result which is probably due to the importance of the public sector especially in continental Europe. Note that this is not due to the different weight on GDP of the two components, which have comparable values in our sample.
\end{abstract}

\section{JEL classification: E62, C33}

Keywords: fiscal policy, private consumption, panel vector autoregression.

\footnotetext{
${ }^{ \pm}$Department of Economics - University of Bologna - Strada Maggiore 45 - 40125 - Bologna (Italy) - Tel: +39 - 0512092606 (email: luigi.marattin@unibo.it)

$\div$ Department of Mathematics for Decisions - University of Florence - Via Lombroso 6/17 - 50134 - Firenze (Italy) (email: salotti@unisi.it)
} 


\section{Introduction}

How does fiscal policy affect private consumption in the EU area? What is the impact on private consumption of increases in (different categories of) public expenditure, taxation or government debt?

The "theoretical divide" on the subject is very well known. In the neoclassical/RBC approach (Baxter and King, 1993), an increase in wasteful government consumption - financed either by debt issuing or tax revenue - increases the net present value of taxation, because Ricardian equivalence holds among intertemporally optimizing consumers. This, in turn, reduces permanent income and the associated negative wealth effect causes a decrease in private consumption and an increase in labour supply. ${ }^{1}$ As a result, a positive government spending shock reduces private consumption and increases output.

On the other hand, Keynesian approaches attempted to rescue a positive relationship between government and private consumption, basically by including additional effects on the above neoclassical chain of events. The combined effects of credit-constrained agents (who are not able to smooth consumption over time and are therefore forced to consume out of their current real wage) and nominal price rigidities (which permit an outward shift of the labour demand curve following the increase in aggregate demand) can cause an increase in real wage and thus an increase in aggregate consumption, as long as the share of credit-constrained agents is quantitatively relevant (Gali et al., 2007). ${ }^{2}$ Recently, Monacelli and Perotti (2008) employed preferences à la Greenwood et al. (1988) so to reduce the size of the outward shift of the labour supply curve following the negative wealth effect. ${ }^{3}$ In this way, with no need of assuming credit-constrained agents, they obtain the increase in the real wage which is needed so to obtain an increase in aggregate consumption, through the standard substitution effect. A large econometric literature has been developed in order to verify the empirical relevance of the two competing approaches. While most of the studies are exclusively based on US economy (Fatas and Mihov, 2001; Blanchard and Perotti, 2002; Gali and Perotti, 2003; Ramey, 2007; Monacelli and Perotti, 2008), very few focus also on selected European countries (Monacelli and Perotti, 2006; Perotti, 2004; Biau and Girard, 2005; Perotti, 2007). Evidence points, generally, towards a positive effect of government expenditure on private consumption, although often results depend

\footnotetext{
${ }^{1}$ This effect assumes that consumption and leisure are normal goods.

${ }^{2}$ In general equilibrium models, the real wage increase occurs if monetary response to output is not too strong so to dampen the increase in labour demand.

${ }^{3}$ See also Schmitt-Grohe and Uribe (2008) and Jaimovich and Rebelo (2009). Other attempts include the consideration of a negative reaction of the mark-up in monopolistic competitive frameworks (Ravn et al., 2006), or an ad-hoc complementarity between labour supply and aggregate consumption in the utility function (Linneman, 2006).
} 
considerably on estimation techniques and identification strategies (see Perotti, 2007 for a detailed survey). However, none of the above contributions is specifically targeted at the European economy as a whole; in fact, they either include one or two EU countries (specifically, UK and West Germany) as a part of a wider analysis that includes also USA and Canada, or are one country-based (Biau and Girard, 2007 on France; Giordano et al,. 2008 on Italy). Exceptions are represented by studies from Beetsma et al. (2006) and Fiorito and Kollintzas (2004), based on 14 and 12 EU countries respectively. However, they both differ substantially from our present contribution. In particular, Beetsma et al. (2006) use a parsimonious three-variables PVAR (with public spending, net taxes and GDP), as the focus of their analysis is different from the links between public spending and private consumption. On the other hand, in Fiorito and Kollintzas (2004) the approach is totally different from the other VAR-based studies cited above, as they perform a GMM estimation of an Euler equation assuming non-separability between private and public consumption in the utility function. ${ }^{4}$

In this article we perform a detailed PVAR analysis on 14 EU countries, using annual data from 1970 to 2006. Firstly, we estimate a 6-variables VAR capable to grasp the effects of fiscal policy on private consumption and investment. Then, we disaggregate public expenditure between wage and non-wage components, to investigate the main responsible for the (expansionary) transmission mechanisms. We back up these analysis with extensive robustness checks.

Our results can be summarized as follows. Generally speaking, increases in government expenditure lead to positive and significant effects on private consumption and private investment. According to our baseline estimate, a $1 \%$ increase in public spending produces a $0.26 \%$ on impact rise in private consumption, and a $0.43 \%$ impact rise in private investment. The effects are substantial, and die out slowly in the case of private consumption ( $0.63 \%$ cumulative impact after 3 years), but much faster in the case of private investment. A further disaggregation between wage and non-wage components reveals that public salaries have a relatively stronger stimulating role, a result which is probably due to the importance of the public sector especially in continental Europe. Note that this is not due to the different weight on GDP of the two components, which have comparable values in our sample. The Keynesian flavour of the above results is softened by two further results: first, public investment does not seem to have any significant stimulating effects on the private sector components of aggregate demand. Secondly, the fiscal multiplier on aggregate consumption is no longer positive when tax

\footnotetext{
${ }^{4}$ Nevertheless, Fiorito and Kollinztas (2004) achieve interesting results in terms of disaggregation of public expenditure; they find that while public goods substitute for private consumption, public expenditure on merit goods seems to
} 
revenue or debt are the policy instruments. In fact, shocks in taxation revenue and government liabilities display a, respectively, positive and negative effects of private aggregate consumption. Therefore, it seems that while Keynes seems to prevail on (part of) the spending side, Ricardo dominates the reaction of aggregate consumption to the tax instruments and the debt financing.

The remainder of this paper is organized as follows. In section 2 we extensively describe the dataset and the strategy to identify exogenous spending shocks. In section 3 we present the baseline estimations and study the responses to shocks in government consumption, as well as the responses of private consumption to the other fiscal variables of the PVAR. Section 4 presents different robustness checks of the baseline results. Finally, section 5 concludes.

\section{Data and estimation strategy}

Our approach is based on a PVAR with annual data. There are two reasons behind the adoption of this particular strategy. First, the PVAR technique combines the traditional VAR approach with panel data, which allows for unobserved individual heterogeneity. While the advantage of using panels consists in an increase in the number of observations, the disadvantage is the need to impose certain homogeneity restrictions. However, by focusing on EU countries only, we limit the potential heterogeneity, as the EU economies share many similarities and are part of a substantially integrated economic area. Second, we use annual rather than quarterly data, unlike a substantial part of the previous empirical literature. One advantage is that, since there is no quarterly calendar for fiscal policy revisions, the interpretation of fiscal shocks may be facilitated. Also, potential anticipation effects of fiscal policy changes play a smaller role with annual data, as identified shocks are more likely to be truly unanticipated (Ramey, 2007).

The structural form of our PVAR model is given by:

$$
A_{0} Z_{i t}=A(L) Z_{i t-1}+e_{i t} \text {, }
$$

where $Z_{i t}$ is an $(m x 1)$ vector of endogenous variables; $A_{0}$ is an (mxn) matrix with 1 's on the diagonal and contains the parameters that capture the contemporaneous relations among the variables; $A(L)$ is a matrix polynomial in the lag operator $L$; finally, $e_{i t}$ is the structural disturbance vector. Pre-multiplying (1) by $A_{0}^{-1}$, we obtain the reduced form that we can actually estimate:

$$
Z_{i t}=B(L) Z_{i t-1}+u_{i t},
$$

complement for it. 
where $B(L)=A_{0}^{-1} A(L)$ and $u_{i t}=A_{0}^{-1} e_{i t}$ is the reduced form residual vector.

In the baseline specification, the vector $\mathrm{Z}$ is as follows: $Z_{i t}=\left[b_{i t}, g c_{i t}, p_{i t}, t_{i t}, i_{i t}, c_{i t}\right]$, where $b_{i t}$ is government gross financial liabilities, $g c_{i t}$ is government expenditure (wage and non wage components), $p_{i t}$ is price level, $t_{i t}$ is net taxes (revenues minus transfers), $i_{i t}$ is private investment, $c_{i t}$ is private consumption. All variables are first differences, real, in logs, per-capita and deflated by their own deflators. ${ }^{5}$

Our identification scheme is based on a lower triangular Cholesky decomposition with the above indicated ordering. Hence, a variable coming earlier in the ordering affects the next ones both contemporaneously and with a lag, while a variable coming later has merely lagged effects on the preceding ones. The main drawback of using annual data is that specific identifying assumptions might be rather strong. In particular, within-year responses of taxes to private consumption are excluded. This assumption is motivated by the fact that more and more often VAT-tax revenue corresponding to year $t$ consumption is registered in official government balance sheet as $t+1$ tax revenue (moreover, VAT is only a portion of overall tax revenue). By the same token, our identification scheme assumes that public expenditure at time $t$ is not affected by contemporaneous tax revenue; this might be reasonable, as spending plans are usually determined before the new fiscal year starts. However, note that we allow government spending to be affected by the existing stock of public debt.

Our sample consists of 14 EU countries (Austria, Belgium, Denmark, Finland, France, Ireland, Italy, Germany, Greece, the Netherlands, Portugal, Spain, Sweden and the United Kingdom) over the period 1970-2006. ${ }^{6}$ Our data are mainly from the OECD Economic Outlook no. 84, but we integrated this source with the Main Economic Indicators (published by the European Commission) and the World Development Indicators (published by the World Bank).

The use of a PVAR approach requires the underlying structure to be the same for each cross-sectional unit. This is likely to be violated in practice, even if focusing on the EU ensures a certain degree of similarity among the countries of the sample. Nevertheless, we allow for individual heterogeneity by introducing fixed effects. Since they are correlated with the regressors due to the lags of the variables, the mean-differencing procedure commonly used to eliminate fixed effects will create biased coefficients. To overcome this problem, we use forward-mean differencing (Helmert procedure, see

\footnotetext{
5 In all the estimates that follow, we have also tried the same specifications using the GDP deflator for all variables, instead of their own deflators. Results do not change significantly.
} 
Arellano and Bover, 1995). This procedure preserves the orthogonality between transformed variables and lagged regressors, thus we use lagged regressors as instruments and estimate the coefficients by system GMM (Love and Zicchino, 2006). ${ }^{7}$

Next section illustrates the results of our analysis. We focus on the impulse-response functions, which describe the reaction of one variable in the system to the innovations of another variable while holding all other shocks at zero (that is, we use orthogonalized shocks).

\section{Estimation results}

The results are presented in two different subsections: the first one (3.1) contains the baseline specification results, while the second one (3.2) deepens the analysis by disaggregating public spending between wage and non wage expenditure. Within each subsection, we look both at the responses of all the variables to government expenditure shocks, and at the response of private consumption to shocks in other variables of the VAR.

\subsection{Government consumption as a whole}

Figure 1 shows the impulse responses for a 1\% increase in government spending (see Table 1 for details). Several remarkable insights can be noticed. First of all, public spending has a positive impact both on private consumption and private investment, in line with the existing empirical results for different economic areas. On impact, the former increases by $0.32 \%$ and the latter by $0.43 \%$. The effects are substantial, and are very persistent in the case of private consumption (positive and statistically significant effects last until the third year from the shock), but much faster in the case of private investment (where a high significance is observed on the contemporaneous effect only). Interestingly, increases in public spending do not have quantitatively significant effect on government debt, because they seem to trigger a parallel positive reaction of tax revenue, so to keep deficit under control.

We find it worthy to deepen the analysis on the private consumption responses to the fiscal variables of the PVAR. Thus, Figure 2 (and Table 2) displays the responses of this variable to shocks in public debt, net taxes and public spending (although this last one is redundant, as already shown in Figure 1).

\footnotetext{
${ }^{6}$ The panel is balanced, apart from very few missing values (Denmark 1970, all series; France 1970-1976, public debt; Portugal 1970-1976, all series). We excluded Luxembourg due to limited availability of fiscal variables.

${ }^{7}$ To perform the analysis we used the Stata pvar routine written by Inessa Love (see Love and Zicchino, 2006).
} 
The positive reaction to fiscal pressure and the negative one to debt seem to indicate evidence of Ricardian behaviour: an increase in tax revenue signals a reduction in future government liabilities and therefore triggers a positive wealth effect. On the other hand, an increase in government debt causes a reduction in the present value of future income, and therefore reduces current consumption.

To conclude with the baseline specification results, we investigate the role of government investment, rather than consumption. This has been done by replacing the latter with the former in our baseline specification. Figure 3 and Table 3 show the impulse responses for a 1\% increase in public investment.

Not surprisingly, given the modest share of government investment on GDP (the average in the sample is $3.2 \%$ ), the responses are quantitatively much smaller. Particularly, there are weak negative effects on private investment (never statistically significant at standard levels), and a very weak positive impact on private consumption, followed by small negative effects (whose statistical significance is never above standard levels).

\subsection{Does the distinction between wage and non-wage expenditure matter?}

The above results point out the existence of positive effects of government current expenditure on private consumption. In this subsection we disaggregate the former in order to draw further insights on its transmission mechanisms to the economy. In what follows we estimate two different PVARs similar to the baseline one: in the first, we replace total public spending with government wage bill ( $g w$ ), while in the second we replace it with government non-wage expenditure $(g n w)$.

Figures 4 and 5 show the impulse responses for an increase in, respectively, government wage and government non wage expenditure (details are to be found in Tables 4 and 5). Even if shocks in wage and non-wage components of public expenditure impact differently on macroeconomic variables, the responses of private consumption are qualitatively and quantitatively consistent to the baseline case.

Comparing the upper right corner panels of the two figures, we notice that the impact of a government wage shock on private consumption is approximately six times bigger than the shock of non-wage expenditure (with similar persistence). A similar phenomenon is true for the response of private investment. Note that this result is not due to the relative weights of the two components, which are almost the same in the sample (government wage spending averages $12.00 \%$ of GDP, while non-wage expenditure is $11.77 \%$. of GDP on average). Some additional results deserve a short discussion. In particular, an increase in public salaries (Figure 4) has a positive and slightly significant impact on public debt, and an inflationary effect; moreover, it does not have a persistent significant stimulating effect on private investment. On the other hand, increases in the non-wage component (Figure 5) have 
negligible effects both on the debt dynamics and on prices.

\section{Robustness checks}

In this section we verify the robustness of the results presented in the previous section. We proceed along three dimensions: the first set of test modifies the PVAR dimension (subsection 4.1); the second checks if the results hold to variations in the sample (subsection 4.2); finally, we estimate our baseline model for two different periods (subsection 4.3). ${ }^{8}$

\subsection{Different VAR dimensions}

Figure 6 shows the responses of both private consumption and private investment to shocks in public spending resulting from five different 5-variables VARs obtained by excluding (one at a time) public debt, net taxes, price level, private investment, private consumption. Figure 7 shows the responses of the same two variables of interest to shocks in public spending, this time resulting from three different 4-variables VARs obtained by excluding the following pairs of variables (one at a time): public debt and net taxes, public debt and price level, price level and net taxes. Only the point estimates are reported. Together with these alternative PVARs responses, also the ones coming from the baseline PVAR are reported (with solid lines).

The responses remain qualitatively the same across all the different specifications. Both private consumption and private investment react positively to shocks in public spending, with the latter being even more stimulated than the first (both in terms of quantitative impact and in terms of persistence of the shocks).

\subsection{Sample variation}

We estimate our PVAR excluding one country member at a time to see if there are single countries driving the results of the whole panel. Figure 8 shows the private consumption and investment responses to shocks in government spending. Solid lines are the responses of the baseline model while dotted lines are the responses excluding one country member at a time.

The figure demonstrates the robustness of the baseline responses to changes in the dataset's

\footnotetext{
${ }^{8}$ Furthermore, we also ran other simple robustness checks (not shown here). For instance, we tried some changes in the variables' order in the VAR; we did not include net social securities in net taxes; we used the GDP deflator to deflate all the variables instead of using the own deflators. Results are never significantly affected.
} 
composition. Only in a few cases the exclusion of one country produces some slight quantitative

differences. ${ }^{9}$ The importance of this particular robustness test is to be particularly emphasized, since it proves the existence of the sample homogeneity that we used as a reason to undertake the panel analysis in the first place.

\subsection{Time variation}

Finally, we perform two last tests by estimating our model on two alternative (and reduced) time spans. First, as some contributions (Perotti, 2004; Romer and Romer, 2007) provide evidence that both the variance of fiscal policy shocks and their effects on consumption have declined after 1980, we estimate our PVAR for the period 1980-2006. Figure 9 shows the impulse response functions of each variable to shocks in government spending. This robustness check shows that the baseline responses are qualitatively robust to this change in the sample period, although both the responses of private consumption and of private investment are slightly smaller than the one estimated from the period 1970-2006, as expected.

Second, as the introduction of the Euro might have affected most countries in our sample, we restrict the sample period to the pre-EMU years (1970-1998). By doing this, we intend to control for potential structural breaks - caused by the monetary policy structural change - in the way fiscal policy affects the economy in the EU countries. Figure 10 shows the impulse response functions of all the variables of the PVAR to shocks in government spending. Again, the check demonstrates that the baseline responses are qualitatively robust to changes in the sample period. The only notable difference is in the persistence of the effects of public spending shocks on private investment, which is now larger.

\section{Conclusions}

The qualitative and quantitative response of private consumption to government expenditure shocks is a strong dividing line between Keynesian and neo-classical macroeconomic approaches. Empirical literature, although far from unambiguous evidence, points towards a positive effect; however the existing contributions have only marginally investigated the EU area, as they mainly looked at few countries individually (particularly United States). In this paper we perform a PVAR analysis on 14 EU countries, using a balanced annual dataset from 1970 to 2006. Our results - robust to a wide range of robustness checks including sample and time variation - can be summarized as follows. First, shocks in

\footnotetext{
${ }^{9}$ Namely, a smaller response of investment when either Finland or Portugal are excluded.
} 
government expenditure lead to positive, persistent and significant effects on private consumption and private investment (respectively, 0.26 and $0.43 \%$ on impact). Second, the disaggregation between wage and non-wage components reveals that public salaries have a relatively stronger stimulating role (both on private consumption and private investment), a result which is probably due to the importance of the public sector, especially in continental Europe. Note that this is not due to the different weight on GDP of the two components, which have comparable values in our sample. Third, we did not find a similar stimulating role for public investment (especially relative to the private counterpart). Finally, private consumption reacts positively to increases in tax revenue and negatively to increases in public debt.

While the first two results push towards a Keynesian world, the last two rescue the Ricardian intuition. Nevertheless, the stimulating role of public expenditure deserves some additional attention: a further and more detailed disaggregation of government spending might be needed, as well as a parallel distinction between purchases of durable and non-durable consumption goods. As the need of finding the most appropriate "exit-strategy" from the massive increase in public expenditure (following the 2008-2009 recession) intensifies, these investigations regarding the usefulness of public money might become more and more useful. 


\section{References}

Arellano, M., Bover, O., 1995. Another Look at the Instrumental Variable Estimation of Error Component Models. Journal of Econometrics 68, pp. 29--51.

Baxter,M, King, R., 1993. Time Separable Preferences and Intertemporal Substitution Models of the Business Cycle. Quarterly Journal of Economics 99, pp. 817--40.

Beetsma, R., Giuliodori, M., Klaassen, F., 2006. Trade Spill-Overs of Fiscal Policy in the European Union: A Panel Analysis. Economic Policy 21(48), pp.639--687.

Biau, O., Girard, E., 2007. Politique budgétaire et dynamique éeconomique en France: l'approche VAR structurel. Économie et Prévision 169-171, pp. 1--24.

Blanchard, O., Perotti, R., 2002. An Empirical Characterization of the Dynamic Effects of Changes in Government Spending and Taxes on Output. Quarterly Journal of Economics117 (4), pp. 1329--1368.

Fatàs, A., Mihov, I., 2001. The Effects of Fiscal Policy on Consumption and Employment: Theory and Evidence. Mimeo, INSEAD.

Fiorito, R., Kollintzas, T., 2004. Public Goods, Merit Goods and the Relation between Private and Government Consumption. European Economic Review 48, pp. 1367--1398.

Gali, J., Lopez-Salido, J., Valles, J., 2007. Understanding the Effects of Government Spending on Consumption. Journal of the European Economic Association 5(1), pp. 227--270.

Gali, J., Perotti, R., 2003. Fiscal Policy and Monetary Integration in Europe. Blackwell.

Giordano, R., Momigliano, S., Neri, S., Perotti, R., 2008. The Effects of Fiscal Policy in Italy: Evidence from a VAR Model. Bank of Italy Discussion Paper 656.

Greenwood, J., Hercowitz, Z., Huffman, G., 1988. Investment, Capacity Utilization and the Real 
Business Cycle. American Economic Review 78, pp. 402--417.

Jaimovich, N., Rebelo, S., 2009. Can News About the Future Drive the Business Cycle?. American Economic Review 99(4), pp. 1097--1118.

Linnemann, L., 2006. The Effect of Government Spending on Private Consumption: A Puzzle? Journal of Money, Credit and Banking 38(7), pp. 1715.

Love, V., Zicchino, L., 2006. Financial Development and Dynamic Investment Behavior: Evidence from Panel VAR. Quarterly Review of Economics and Finance 46(2), pp. 190--210.

Monacelli, T., Perotti, R., 2006. Fiscal Policy, the Trade Balance and the Real Exchange Rate: Implications for International Risk Sharing. Manuscript, IGIER - Bocconi.

Monacelli, T., Perotti, R., 2008. Fiscal Policy,Wealth Effects and Mark-Ups. NBER Working Paper No. 14584.

Monacelli, T., Perotti, R., 2008. Openness and the Sectoral Effects of Fiscal Policy. Journal of the European Economic Association 6(2-3), pp. 395--403.

Perotti, R., 2004. Estimating the Effects of Fiscal Policy on OECD Countries. Working Paper, IGIERBocconi.

Perotti, R., 2007. In Search of the Transmission Mechanism of Fiscal Policy. Working Paper, IGIERBocconi.

Ramey, V.A., 2007. Identifying Government Spending Shocks: It’s All in the Timing. Manuscript, University of California, San Diego.

Ravn, M., Schmitt-Grohè S., Uribe, M., 2006. Deep Habits. Review of Economic Studies 73(1), pp. 195--218. 
Romer, C. and Romer, D., 2007. The Macroeconomic Effects of Tax Changes: Estimates Based on a New Measure of Fiscal Shocks. Working paper, University of California, Berkeley.

Schmitt-Grohè, S., Uribe, M., 2008. What's 'News' in Business Cycle. NBER Working Paper No.14215. 


\section{Figures}

Figure 1: baseline impulse responses (shock in public spending)
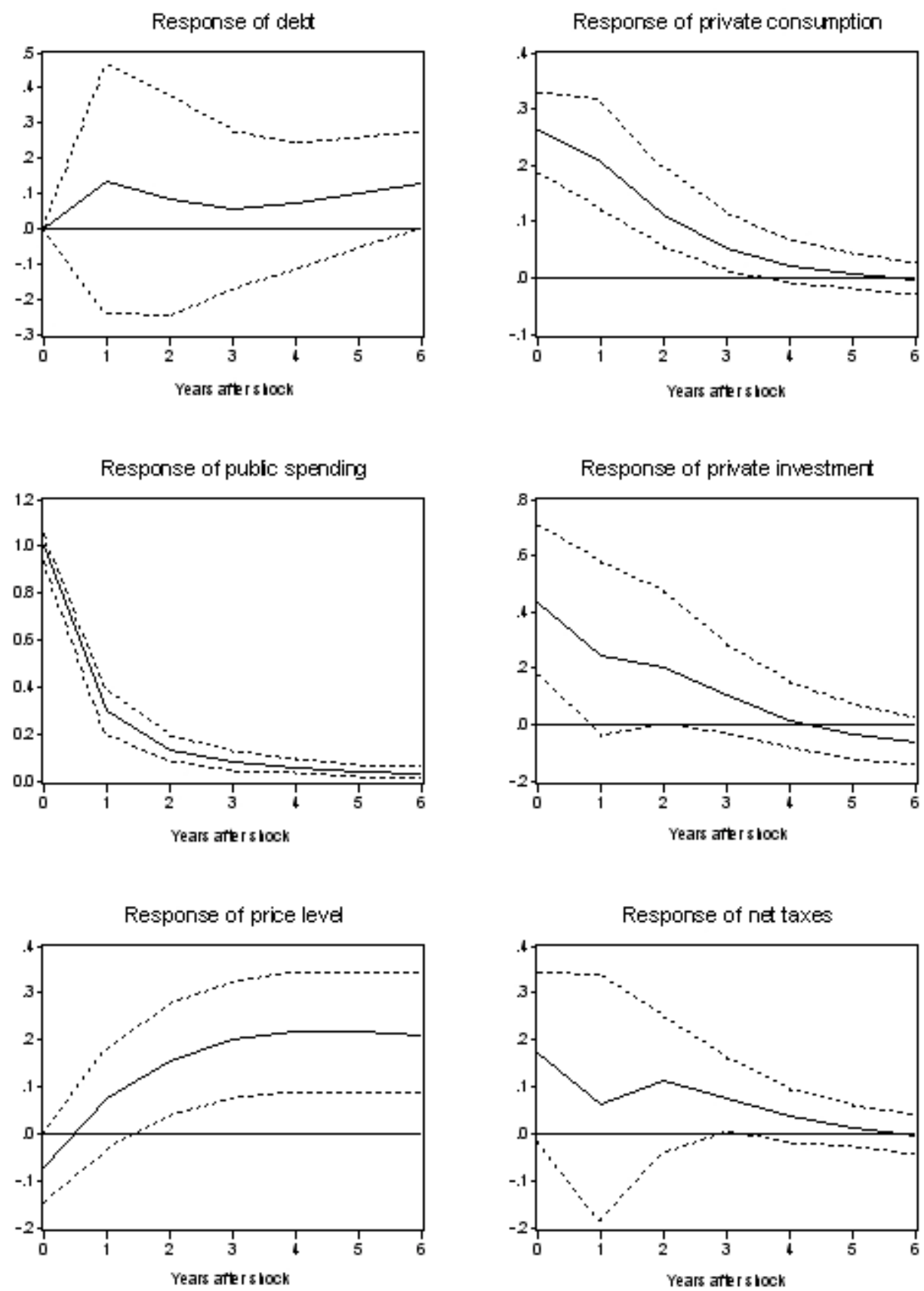

Note: Confidence bands are the 5th and 95th percentiles from Monte Carlo simulations based on 200 replications. 
Figure 2: baseline responses of private consumption to shocks in fiscal variables
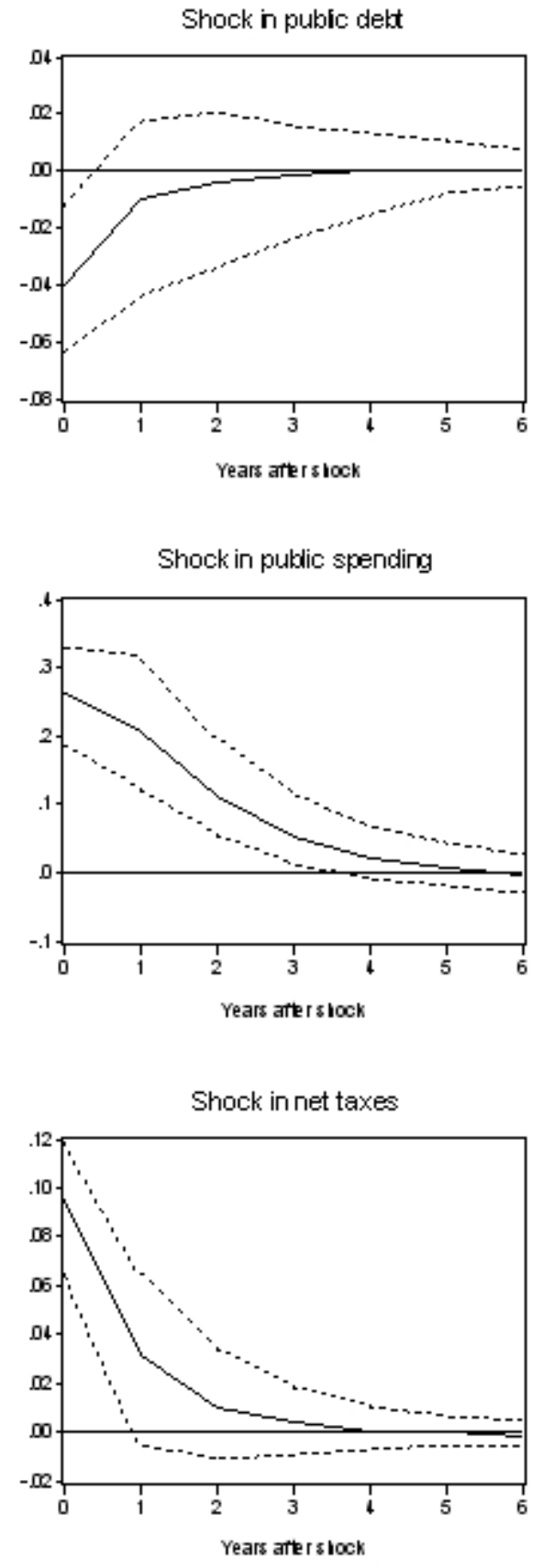

Note: Confidence bands are the 5th and 95th percentiles from Monte Carlo simulations based on 200 replications. 
Figure 3: impulse responses (shock in public investment)
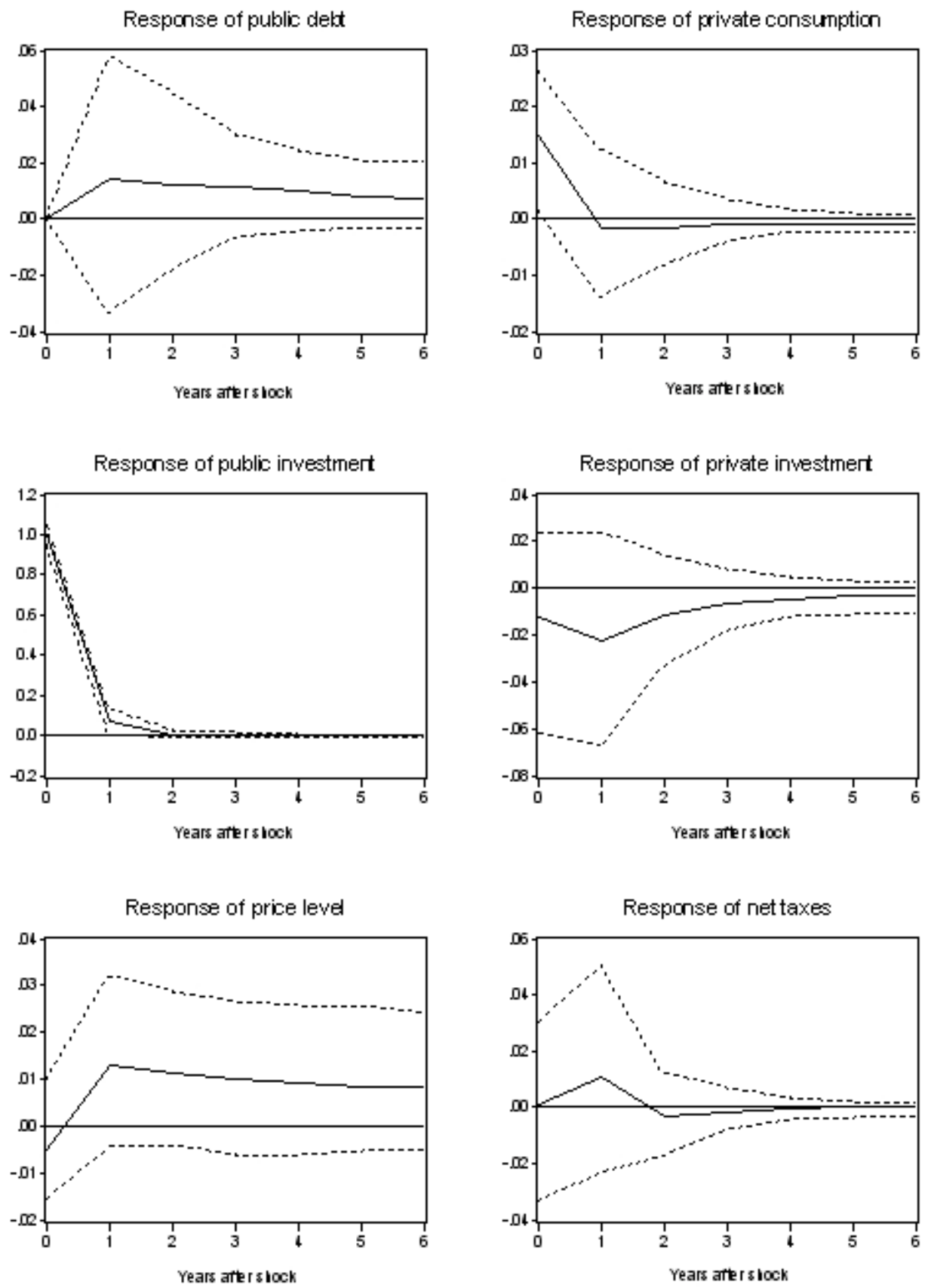

Note: Confidence bands are the 5th and 95th percentiles from Monte Carlo simulations based on 200 replications. 
Figure 4: impulse responses (shock in government wage expenditure)
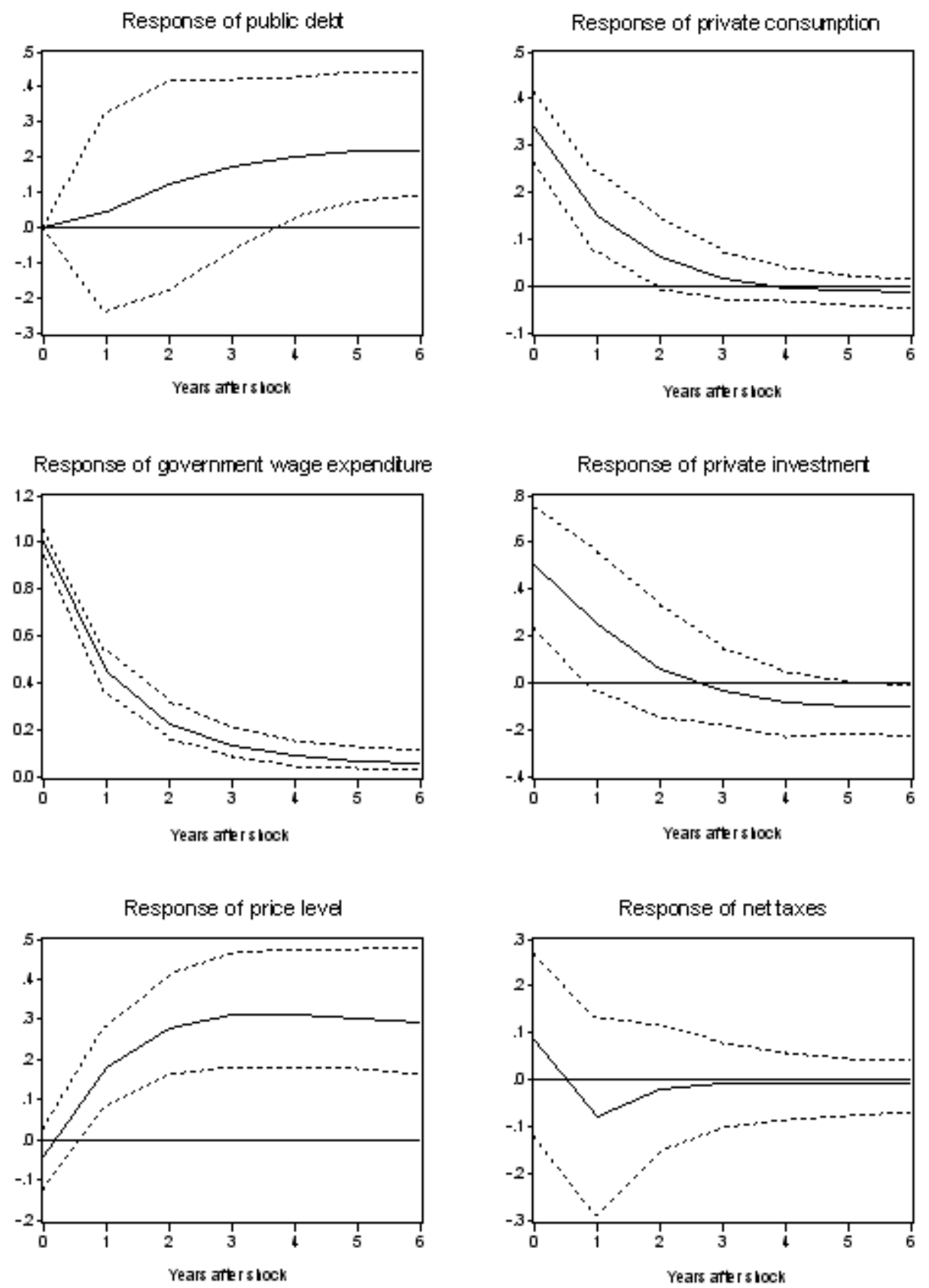

Note: Confidence bands are the 5th and 95th percentiles from Monte Carlo simulations based on 200 replications. 
Figure 5: impulse responses (shock in government non wage expenditure)
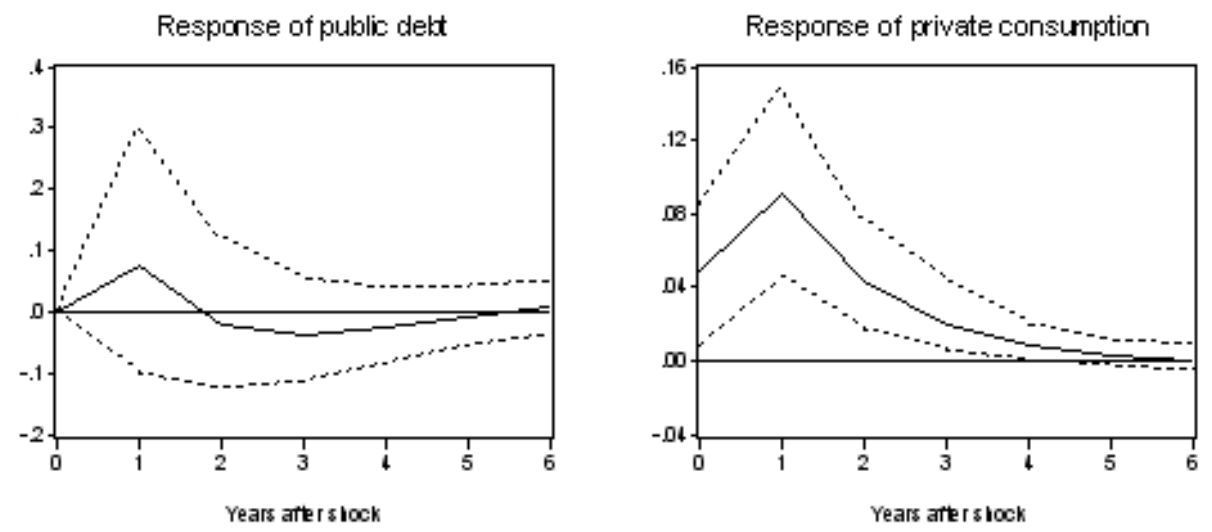

Response of government non wage expendture
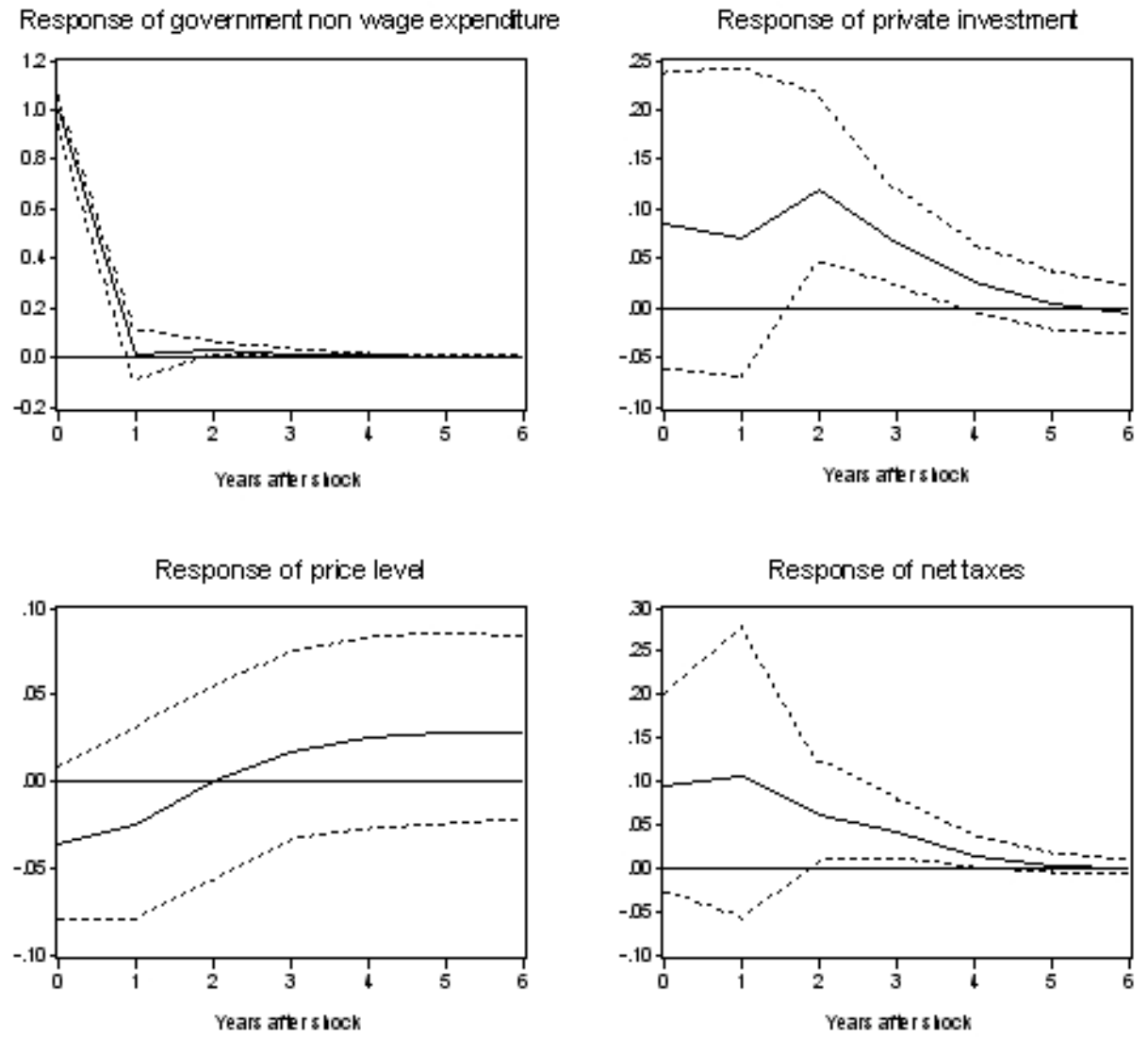

Note: Confidence bands are the 5th and 95th percentiles from Monte Carlo simulations based on 200 replications. 
Fig. 6: robustness check, private consumption and investment responses (shock in public spending - point estimates only), 5-variables VARs
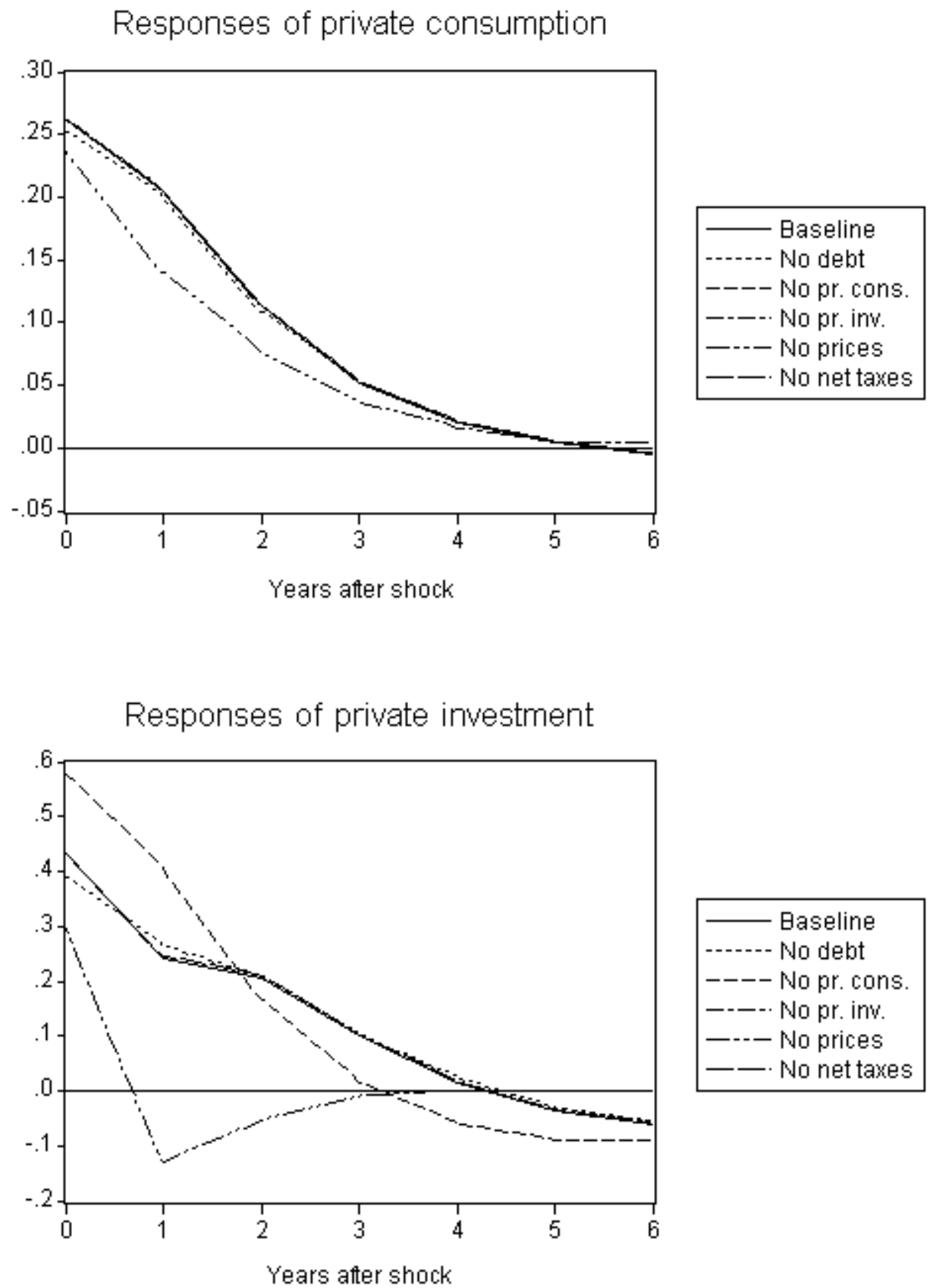

Note: solid lines are the baseline VAR estimates; dotted lines are the point estimates of the impulse responses coming from five different 5-variables VARs obtained by excluding the indicated variables one at a time. 
Fig. 7: robustness check, private consumption and investment responses (shock in public spending - point estimates only), 4-variables VARs

\section{Responses of private consumption}
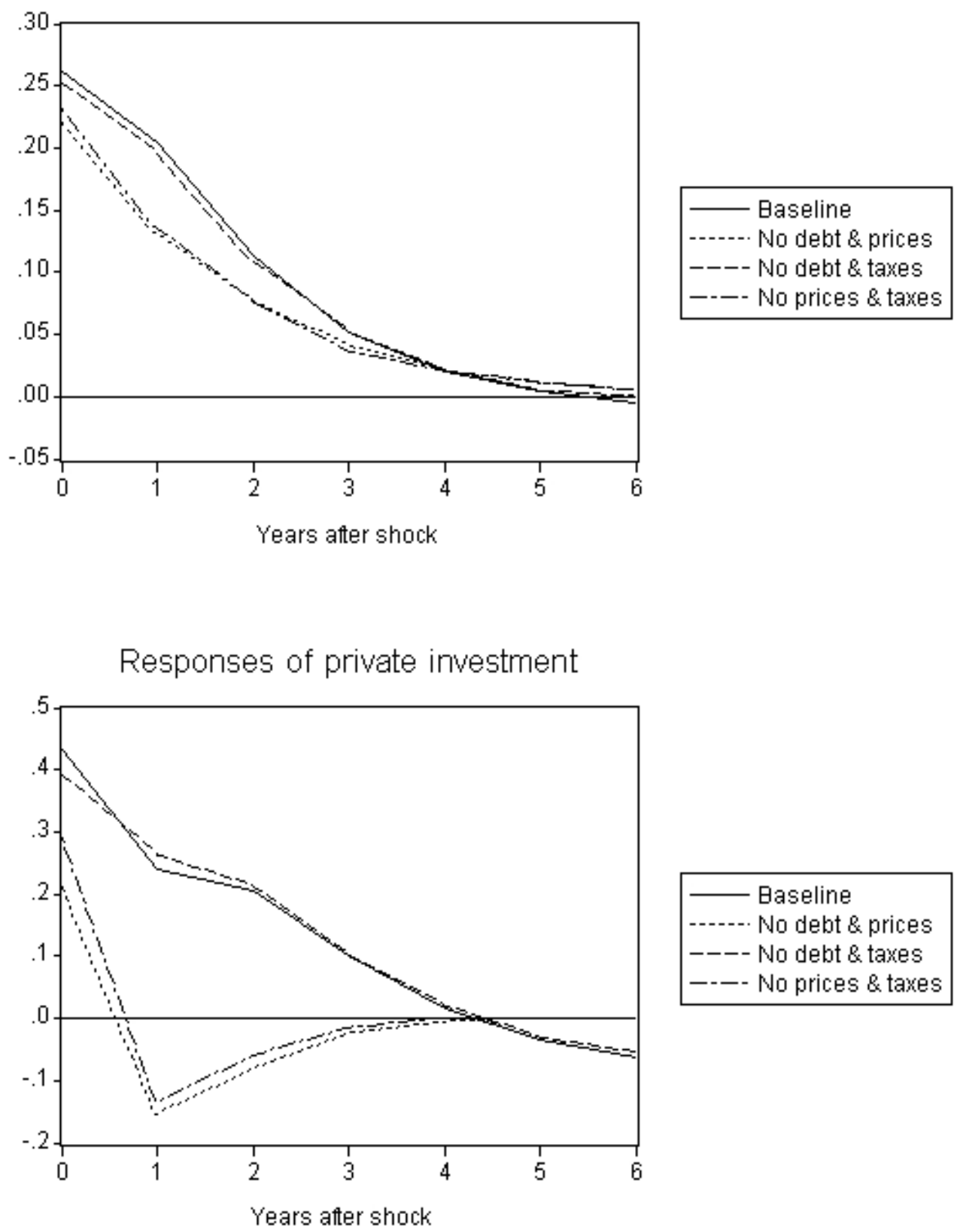

Note: solid lines are the baseline VAR estimates; dotted lines are the point estimates of the impulse responses coming from three different 4-variables VARs obtained by excluding the indicated pairs of variables one at a time. 
Figure 8: robustness check, private consumption and investment responses (shock in public spending - point estimates only), sample variation
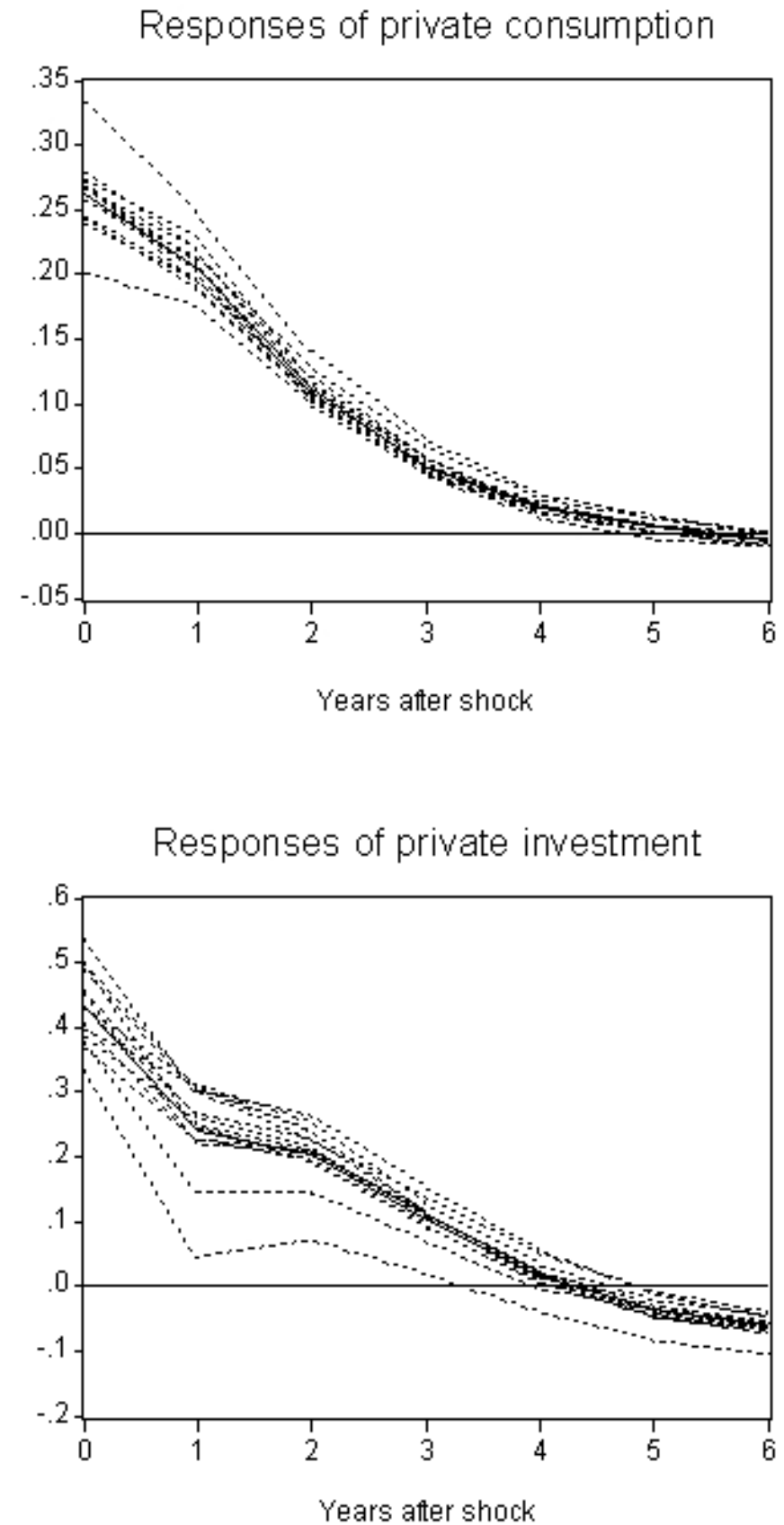

Note: solid lines are the baseline VAR estimates; dotted lines are the point estimates of the impulse responses coming from the fourteen different VARs obtained by excluding one country of the sample at a time. 
Figure 9: impulse responses (shock in public spending), post 1980 period
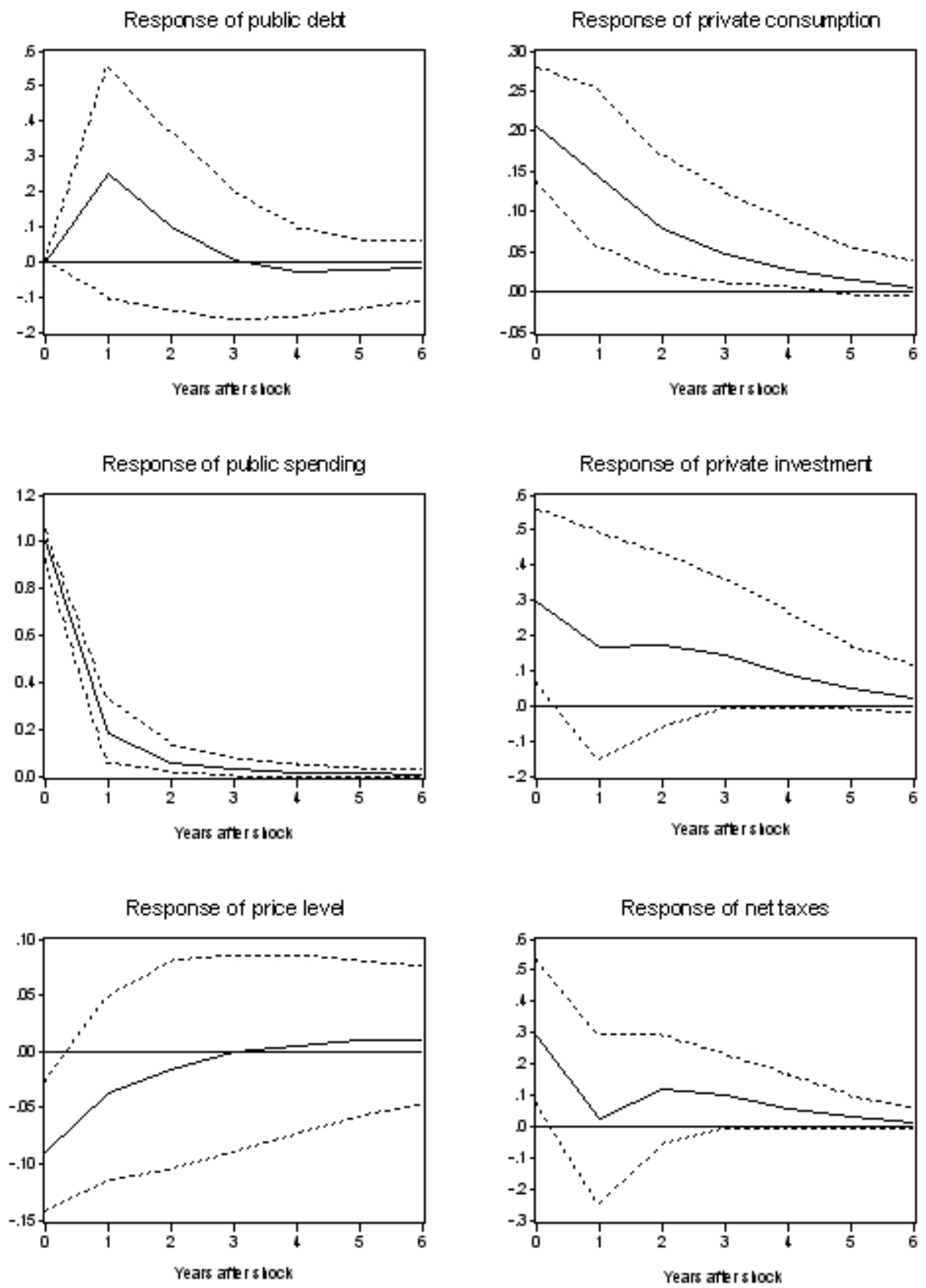

Note: Confidence bands are the 5th and 95th percentiles from Monte Carlo simulations based on 200 replications. 
Figure 10: impulse responses (shock in public spending), pre-EMU period
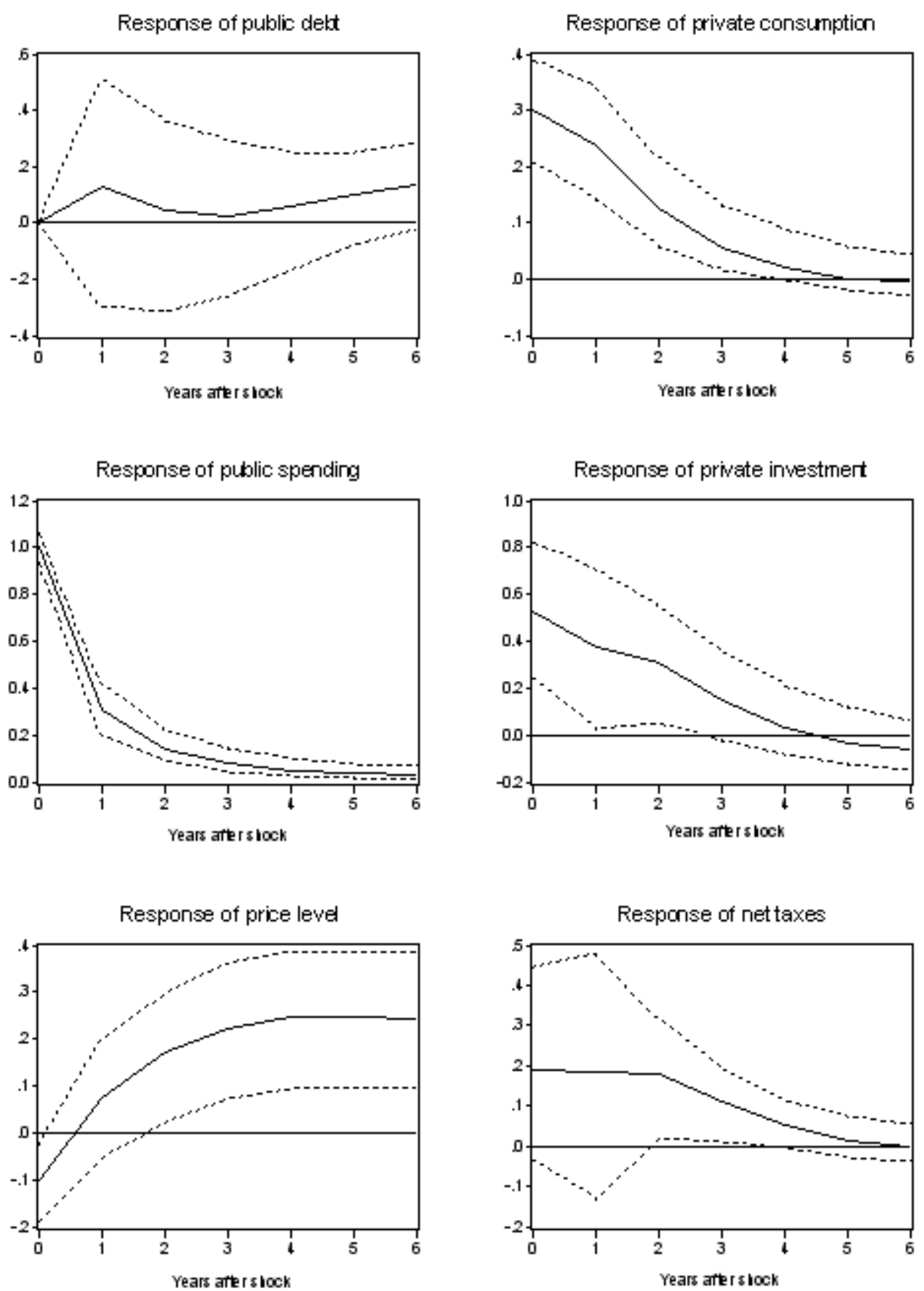

Note: Confidence bands are the 5th and 95th percentiles from Monte Carlo simulations based on 200 replications. 


\section{Tables}

Table 1. Responses to a 1\% fiscal spending ( $g c)$ shock

\begin{tabular}{ccccccc}
\hline Response of $\rightarrow$ & $b$ & $g c$ & $p$ & $t$ & $i$ & $c$ \\
& & & & & & \\
\hline 0 & 0.00 & $1.00^{* * *}$ & $-0.07^{*}$ & $0.17^{*}$ & $0.43^{* * *}$ & $0.26^{* * *}$ \\
1 & 0.13 & $0.30^{* * *}$ & 0.08 & 0.06 & 0.24 & $0.21^{* * *}$ \\
2 & 0.08 & $0.13^{* * *}$ & $0.15^{* *}$ & 0.11 & $0.21^{*}$ & $0.11^{* * *}$ \\
3 & 0.06 & $0.08^{* * *}$ & $0.20^{* * *}$ & $0.08^{*}$ & 0.10 & $0.05^{* *}$ \\
4 & 0.07 & $0.05^{* * *}$ & $0.22^{* * *}$ & 0.04 & 0.02 & 0.02 \\
5 & 0.10 & $0.04^{* * *}$ & $0.22^{* * *}$ & 0.01 & -0.03 & 0.01 \\
6 & 0.13 & $0.03^{* * *}$ & $0.21^{* * *}$ & -0.01 & -0.06 & -0.01 \\
\hline
\end{tabular}

$* * *, * *, *$ : significant at 1,5 and $10 \%$

Table 2. Responses of private consumption (c) to a fiscal variables $(d, t, g c)$ shocks

\begin{tabular}{cccc}
\hline Shock in $\rightarrow$ & $b$ & $g c$ & $t$ \\
& & & \\
\hline 0 & $-0.04^{* * *}$ & $0.26^{* * *}$ & $0.09^{* * *}$ \\
1 & -0.01 & $0.21^{* * *}$ & $0.03^{*}$ \\
2 & -0.00 & $0.11^{* * *}$ & 0.01 \\
3 & -0.00 & $0.05^{* *}$ & 0.00 \\
4 & 0.00 & 0.02 & 0.00 \\
5 & 0.00 & 0.01 & 0.00 \\
6 & 0.00 & -0.01 & -0.00 \\
\hline$* * *, * *, *$ significant at 1,5 and $10 \%$ &
\end{tabular}


Table 3. Responses to a $1 \%$ government investment (gi) shock

\begin{tabular}{ccccccc}
\hline Response of $\rightarrow$ & $b$ & $g i$ & $p$ & $t$ & $i$ & $c$ \\
& & & & & & \\
\hline 0 & 0.00 & $1.00^{* * *}$ & -0.00 & 0.00 & -0.01 & $0.01^{* *}$ \\
1 & 0.01 & $0.07^{*}$ & 0.01 & 0.01 & -0.02 & -0.00 \\
2 & 0.01 & 0.00 & 0.01 & -0.00 & -0.01 & -0.00 \\
3 & 0.01 & -0.00 & 0.01 & -0.00 & -0.01 & -0.00 \\
4 & 0.01 & -0.00 & 0.01 & -0.00 & -0.00 & -0.00 \\
5 & 0.01 & -0.00 & 0.01 & 0.00 & -0.00 & -0.00 \\
6 & 0.01 & -0.00 & 0.01 & 0.00 & -0.00 & -0.00 \\
\hline
\end{tabular}

***, **, *: significant at 1, 5 and $10 \%$

Table 4. Responses to a 1\% government wage expenditure ( $g w$ ) shock

\begin{tabular}{ccccccc}
\hline Response of $\rightarrow$ & $b$ & $g w$ & $p$ & $t$ & $i$ & $c$ \\
& & & & & & \\
\hline 0 & 0.00 & $1.00^{* * *}$ & -0.04 & 0.09 & $0.51^{* * *}$ & $0.34^{* * *}$ \\
1 & 0.05 & $0.45^{* * *}$ & $0.18^{* * *}$ & -0.08 & 0.25 & $0.15^{* * *}$ \\
2 & 0.13 & $0.23^{* * *}$ & $0.28^{* * *}$ & -0.02 & 0.06 & 0.06 \\
3 & 0.18 & $0.13^{* * *}$ & $0.31^{* * *}$ & -0.01 & -0.04 & 0.02 \\
4 & $0.20^{* *}$ & $0.09^{* * *}$ & $0.31^{* * *}$ & -0.01 & -0.09 & -0.01 \\
5 & $0.22^{* *}$ & $0.07^{* * *}$ & $0.30^{* * *}$ & -0.01 & $-0.11^{*}$ & -0.01 \\
6 & $0.22^{* * *}$ & $0.06^{* * *}$ & $0.29^{* * *}$ & -0.01 & $-0.11^{*}$ & -0.02 \\
\hline
\end{tabular}

$* * *, * *, *$ : significant at 1,5 and $10 \%$ 
Table 5. Responses to a 1\% government non-wage expenditure (gnw) shock

\begin{tabular}{ccccccc}
\hline Response of $\rightarrow$ & $b$ & $g n w$ & $p$ & $t$ & $i$ & $c$ \\
& & & & & & \\
\hline 0 & 0.00 & $1.00^{* * *}$ & -0.04 & 0.09 & 0.09 & $0.05^{* *}$ \\
1 & 0.07 & 0.01 & -0.03 & 0.11 & 0.07 & $0.09^{* * *}$ \\
2 & -0.02 & $0.03^{* * *}$ & 0.00 & $0.06^{* *}$ & $0.12^{* * *}$ & $0.04^{* * *}$ \\
3 & -0.04 & $0.01^{*}$ & 0.02 & $0.04^{* *}$ & $0.07^{* * *}$ & $0.02^{* *}$ \\
4 & -0.03 & 0.01 & 0.03 & 0.01 & 0.03 & $0.01^{*}$ \\
5 & -0.01 & 0.00 & 0.03 & 0.00 & 0.00 & 0.00 \\
6 & 0.01 & 0.00 & 0.03 & 0.00 & -0.01 & 0.00 \\
\hline
\end{tabular}

$* * *, * *, *$ : significant at 1,5 and $10 \%$ 